\title{
Production of Calanus chilensis in the upwelling area of Antofagasta, northern Chile
}

\author{
Ruben Escribano ${ }^{1, *}$, Ian McLaren ${ }^{2}$ \\ ${ }^{1}$ Instituto de Investigaciones Oceanológicas, Universidad de Antofagasta, PO Box 170, Antofagasta, Chile \\ ${ }^{2}$ Department of Biology, Dalhousie University, Halifax, Nova Scotia B3H 4J1, Canada
}

\begin{abstract}
Salinities, temperatures, chlorophyll a (chl a), and quantitative samples of Calanus chilensis were obtained at $\sim 17$ d intervals from June 1996 to June 1997 at 3 stations in the Bay of Mejillones, northern Chile, and from 53 stations in a broad-scale survey of surrounding waters from 17 to 21 December 1996. Temporal variability in cohort structure precluded direct estimates of production from samples. However, lack of relationship of eggs per female and stage-frequency distribution with chl a in the broad survey, the apparently continuous development (and presence of adult males) during the time series, and the seasonal correlation of female body size with temperature, but not chl $a_{i}$ all suggest that food supply did not determine production rates. Therefore, temperature-dependent production was estimated, from sample biomasses and from laboratory rearings of $C$. chilensis and other species, as $45 \mathrm{mg} \mathrm{C} \mathrm{m} \mathrm{m}^{-3} \mathrm{r}^{-1}$. This is substantially lower than comparable estimates for $C$. finmarchicus off eastern Canada and nor theastern USA. However, broad-scale production in December 1996 was much higher than that at the 3 time-series stations. A production:biomass ratio of 45, compared with 8 for $C$. finmarchicus off eastern Canada, is compatible with the general view that the upwelling area off northern Chile is part of one of the world's most productive marine systems.
\end{abstract}

KEY WORDS: Calanus $\cdot$ Temperature $\cdot$ Growth $\cdot$ Development $\cdot$ Humboldt Current $\cdot$ Chlorophyll

\section{INTRODUCTION}

Herbivorous zooplankton production may have a crucial influence on the variability of pelagic fish in the Humboldt Current ecosystem. Among the planktonic herbivores, the copepod Calanus chilensis is very abundant (Heinrich 1973) and this has prompted studies of factors that may control its development and growth rates (e.g. Escribano \& Rodriguez 1995, Escribano et al. 1997). The importance of food in limiting zooplankton production is debated. Huntley \& Lopez (1992) concluded in a wide-ranging review that temperature alone might account for variation of growth rates among copepod species. This suggestion, however, has been challenged by Kleppel et al. (1996), who argued that Huntley \& Lopez's (1992) conclusions were based on inappropriately long time scales for the underlying causal relationships. It seems that the evi-

•E-mail: escriban@Ieuna.cl dence for food-limited growth ought to be examined for every particular situation.

The area off Antofagasta, northern Chile $\left(23^{\circ} \mathrm{S}\right)$, is known to be an actively upwelling zone (Fonseca \& Farias 1987, Rodriguez et al. 1991, Marin et al. 1993), providing high rates of primary production in nearshore waters (Marin et al. 1993). Upwelling may occur year round in the area (Fonseca \& Farias 1987), suggesting that phytoplankton production is high in all seasons and consequently may promote continuous growth of zooplankters like Calanus chilensis. In the upwelling area off Antofagasta this species is present through the year and has a multigenerational life cycle (Escribano \& Rodriguez 1994), suggesting that its population growth is not food-limited (Escribano \& Rodriguez 1995). On the other hand, it may show retarded development rates in the laboratory at food levels likely to be found in nature (Escribano et al. 1997).

In some temperate localities where seasonality imposes initial synchrony, so that cohorts are distinguishable in successive samples, it is possible to estimate 
development rates (e.g. McLaren 1978) and production (e.g. McLaren et al. 1989a) directly from nature and compare these with expectations for prevailing temperatures. However, if patterns of development are complex in space and time so that cohorts cannot readily be followed in samples, indirect evidence for independence from food supply must be found before temperature-dependence of production is assumed. Here, we examine such indirect evidence and then estimate production rates of Calanus chilensis, based on field samples and on published work on development of $C$. chilensis and other Calanus species under food-satiated conditions in the laboratory. We also conclude that, because of great local variability in population abundances and structures, local estimates of production are not widely applicable in such upwelling systems.

\section{METHODS}

Sampling and sample processing. A 1 yr time series of samples was obtained at 3 stations in the northern Bay of Mejillones (northern Chile) (Fig. 1). In addition, a broad-scale survey of 53 stations was carried out from 17 to 21 December 1996 from Mejillones to Antofagasta (Fig. 1) to assess the wider patterns of distribution and production at this spring-summer season.

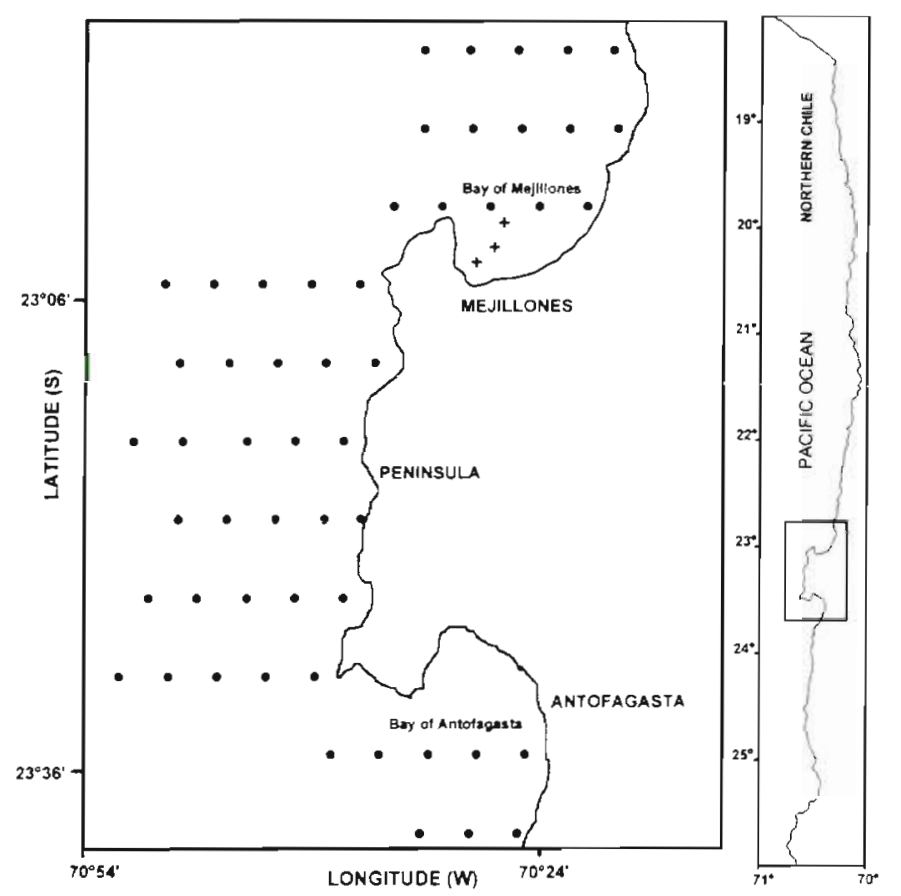

Fig. 1. Peninsula Mejillones (northern Chile), indicating the stations used for a Calanus chilensis broad-scale survey ( and a time series sampling at 3 stations $(+)$ in the northern Bay of Mejillones
During the cruise of December 1996, each station was sampled as follows: a Hensen-type net, with $200 \mu \mathrm{m}$ mesh, equipped with a double closing-opening mechanism and a General Oceanics flowmeter, was used to sample the upper $200 \mathrm{~m}$ strata. Nearshore stations $(<100 \mathrm{~m})$ were sampled from near the bottom to the surface. Nets were vertically towed at about $1 \mathrm{~m}$ $\mathrm{s}^{-1}$. Zooplankton samples were preserved in $5 \%$ neutralized formalin. At each sampling station, from $200 \mathrm{~m}$ (or bottom) to surface, Conductivity-TemperatureDepth (CTD) profiles were obtained with a SeaBird SBE-19. An additional CTD, Ocean Sensor CTD model OS200, equipped with a Westar fluorometer, was deployed down to $100 \mathrm{~m}$.

For the time series in the Bay of Mejillones, zooplankton samples were obtained at an average $17 \mathrm{~d}$ interval at 3 stations (Fig. 1) between June 1996 and June 1997. Two nets were used: one with $200 \mu \mathrm{m}$ mesh, and the other with $100 \mu \mathrm{m}$ mesh, both with openings of $0.5 \mathrm{~m}$. Between them, the nets were assumed to be able to capture all stages of Calanus chilensis. The nets were vertically towed from near the bottom (ca $90 \mathrm{~m}$ at the deepest station) to surface. General Oceanics flowmeters were used to estimate volume filtered by each net. Samples were preserved in $5 \%$ neutralized formalin for later analysis. CTD profiles were also obtained at each station, as described above. In addition, at the central station, 1 I Nansen bottles were deployed at 5 depths to obtain samples to measure chlorophyll a (chl a) concentration, using the spectrophotometric method (Strickland \& Parsons 1972). Samples for chl a were filtered through $0.45 \mu \mathrm{m}$ Millipore filters and kept overnight in the dark at low temperature $\left(6^{\circ} \mathrm{C}\right)$. The extracts were then used to estimate chl a by measuring absorbance at wavelengths of 680,750 and $630 \mathrm{~nm}$ using a Spectronic 20 spectrophotometer. Measurements of chl a were used for an in situ calibration of the fluorometer.

In the laboratory, preserved samples were sorted, and all stages including eggs and nauplii were identified and counted from each net. Copepodids and adults were assumed to be equally well sampled by the 100 and $200 \mu \mathrm{m}$ nets, but nauplii and eggs were assumed to be fully retained only by the $100 \mu \mathrm{m}$ mesh net. Dry weights were obtained for copepodids CI to adult. Individuals were first measured in prosome length under the microscope (to the nearest $0.1 \mathrm{~mm}$ ), using a calibrated micrometer, then rinsed in distilled water, dried for $12 \mathrm{~h}$ at $70^{\circ} \mathrm{C}$ and weighed by 3 or 4 readings to the nearest $10 \mu \mathrm{g}$, using a Denver 250D microbalance. Copepodids CV and adult males and females were individually weighed, while earlier stages were weighed as small groups of individuals. Stages $\mathrm{Cl}$ were weighed in groups of 8 to $10, \mathrm{CII}$ in groups of 5 to 8, CIII in groups of 3 to 5 and CIV as 2 or 3 individuals. All copepodid weights were increased by 
$30 \%$ to compensate for potential losses after formalin preservation (Omori \& Ikeda 1984). Dry weight of eggs was estimated as $0.46 \mu \mathrm{g}$ using diameter measurements and assuming the relation between egg volume and egg carbon given by Huntley \& Lopez (1992). Carbon content was taken as 0.40 of dry weight. The dry weight of combined naupliar stages was estimated as $1.95 \mu \mathrm{g}$, the logarithmic mean value of egg and Cl.

Estimating production. Copepod production was estimated from weight-specific growth rates $\left(g_{i}\right)$ of copepodids and nauplii and biomasses obtained from mean dry weights and numbers per $\mathrm{m}^{3}$ of developmental stages for each sampling date. Growth between successive stages was assumed to be exponential. Thus $g_{i}$ between stages could be estimated as

$$
g_{\mathrm{i}}=\left(\ln \left(W_{1+1} / W_{1}\right)\right) / D_{1}
$$

where $W_{1+1}$ and $W_{i}$ are mean dry weights ( $\mu$ g) of 2 successive stages, and $D_{i}$ is midpoint development time (d) between the 2 stages. $D_{1}$ was assumed to be a function of temperature. According to the equiproportionality rule of development (Corkett et al. 1986), at any temperature the proportion of time occupied by each stage remains constant, when food and other conditions are not limiting. Thus, embryonic durations can be used to specify relative responses to temperature of other developmental stages

The temperature-dependent development embryonic duration of Calanus chilensis was empirically derived by Escribano et al. (1998) as

$$
D=747.7(T+11.0)^{-2.05}
$$

where $D=$ embryonic time (d) and $T$ is temperature $\left({ }^{\circ} \mathrm{C}\right)$. The value 747.7 represents the parameter $a$ of the Beléhrâdek model. Escribano et al. (1998) also estimated that the median time from egg hatching to copepodid $\mathrm{Cl}$ was $7.4 \mathrm{~d}$ at a constant temperature of $15^{\circ} \mathrm{C}$. Although Escribano et al. (1998) were able to rear C. chilensis from egg to adult at a constant temperature of $15^{\circ} \mathrm{C}$ and supposedly satiating food conditions, there was evidence of severe retardation of some individuals after CI. Late stages are known to be more susceptible to laboratory conditions (e.g. Lopez 1991, Carlotti \& Nival 1992) giving rise to large variances and presence of abnormally slow-developing individuals (McLaren et al. 1989b). Thus, development times of later stages of copepods in the laboratory may not represent those possible in the field. The equiproportional rule of development, on the other hands, yields quite uniform relative durations of copepodid stages among several Calanus species (Corkett et al. 1986). In order to avoid uncertainty of development times of later copepodids in the laboratory, we decided to use the Beléhrâdek equation (Eq. 2) to estimate development from hatching to the mean time to reach $\mathrm{CI}$ as follows.
From Eq. (2) the parameter a of the Beléhrâdek equation for development from hatching to $\mathrm{Cl}$ is

$$
a=7.4(15+11)^{+2.05}=5887
$$

Thus the time between hatching and CI could be estimated as

$$
D_{1}=5887(T+11.0)^{-2.05}
$$

Then the time between hatching and subsequent copepodid stages can be estimated as

$$
D_{1}=p_{1}\left[5887(T+11.0)^{-2.05}\right]
$$

where $p_{i}$ is the average proportion of time to each copepodid mid-stage relative to the time from hatching to CI, as the average for several species of Calanus as tabulated by Corkett et al. (1986).

Eq. (3) was applied using field temperatures through the sampling year. Temperature at $10 \mathrm{~m}$ was chosen as better representing the habitat temperature experienced by the population. The thermocline as well as chlorophyll maxima were located near this depth for most of the year. It is well known that adult body size is negatively correlated to temperature through seasons (e.g. Deevey 1964), and female prosome lengths of Calanus chilensis showed the highest correlation with temperature at $10 \mathrm{~m}$, as compared to SST and mean temperature of the water column.

After application of Eq. (1) to estimate instantaneous growth rates between stages, the daily production rates $(P R)$ per stage were estimated as

$$
P R=B_{1}\left(\mathrm{e}^{g_{i}}-1\right)
$$

where $B_{l}$ is the observed biomass ( $\mu \mathrm{g}$ dry weight $\mathrm{m}^{-3}$ ) for stage $i$ and $g_{i}$ is as defined in Eq. (1).

Annual production was calculated by integrating the year cycle as

$$
P=\sum_{i=1}^{n} P R_{i} t i
$$

where $P$ is annual production ( $\mathrm{mg}$ dry weight $\mathrm{m}^{-3} \mathrm{yr}^{-1}$ ), $i$ is the time interval and $t$ is the number of days between time intervals.

To analyze spatial variability of $P R$ during the December 1996 survey, $g_{i}$ was estimated for each sampling station from mean dry weights of stages and application of Eq. (3), again using observed temperatures at $10 \mathrm{~m}$ depth to estimate $D_{1}$.

\section{RESULTS}

\section{Spatial distributions during December 1996}

During the cruise of December 1996, the sea surface temperature (SST) measured in situ ranged from 16.0 to $20.9^{\circ} \mathrm{C}$. As shown by a satellite image obtained dur- 


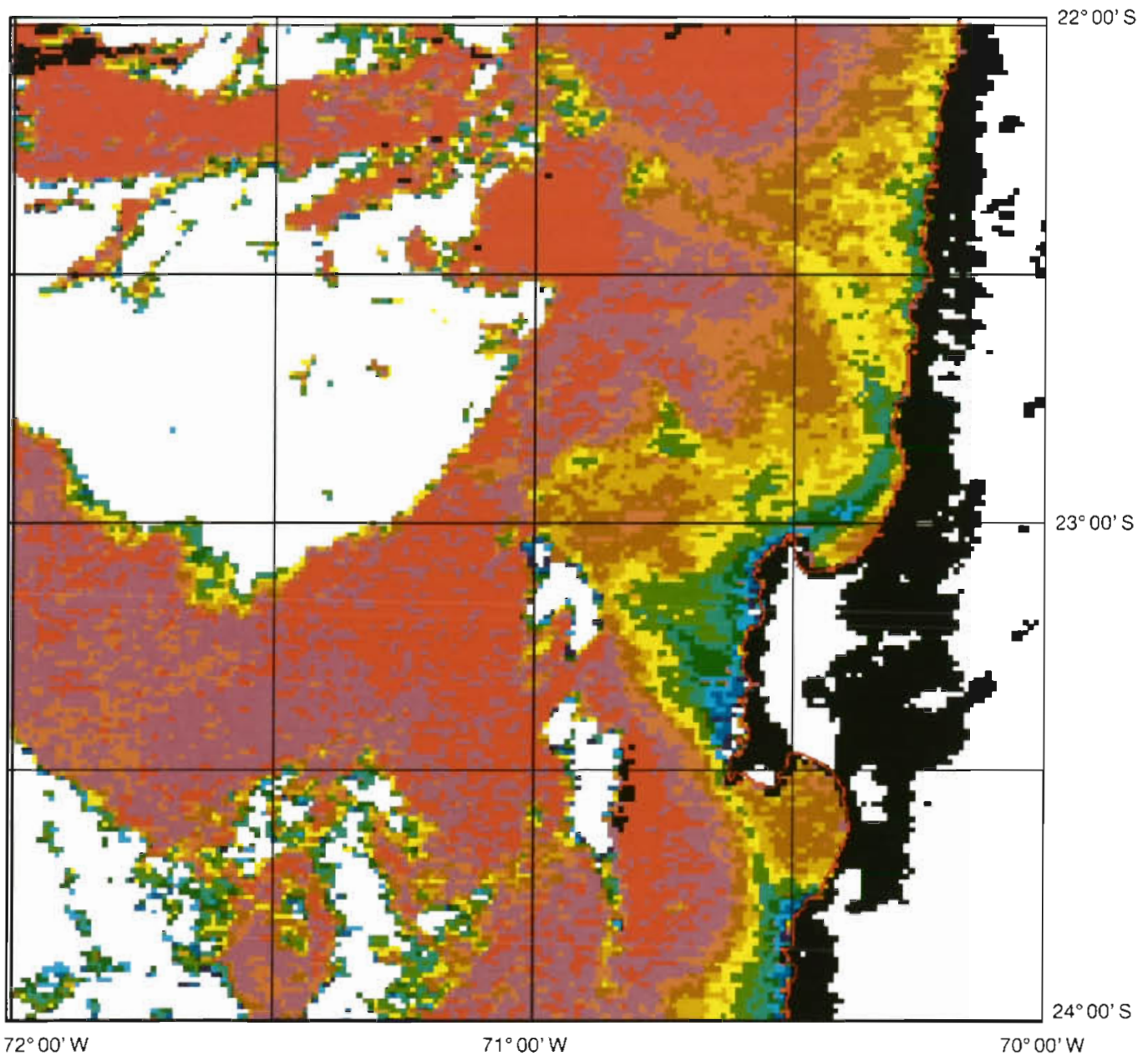

SST $\left({ }^{\circ} \mathrm{C}\right)$

$15.0-15.5$

$15.5-16.0$

$16.0-16.5$

$16.5-17.0$

$17.0-17.5$

$17.5-18.0$

$18.0-18.5$

$18.5-19.0$

$19.0-19.5$

$19.5-20.0$

$20.0-20.5$

$20.5-21.0$

Fig. 2. Sea surface temperature (SST) in the coastal area of Peninsula Mejillones on December 22. 1996, as estimated from a NOAA satellite image ing the sampling (Fig. 2), cold water was mostly located nearshore, indicating that upwelling was active at the time. Although somewhat weakened by high chl a levels 'downstream' of the cool, upwelled water in the Bay of Mejillones, the negative correlation of surface chl a with SST was highly significant ( $\mathrm{r}=$ $-0.607, p<0.001$ ). The correlation of the water-column maximum chl a with temperature at $10 \mathrm{~m}$ was considerably weaker ( $\mathrm{r}=-0.334, \mathrm{p}=0.014)$. It can be seen (Fig. 1) that the 3 stations chosen for the time-series sampling were outside the area of upwelling and high chl a levels in December 1996 (Fig. 2).

There were profound differences in abundances of copepods among the stations sampled in December 1996 (Fig. 3). Stepwise regression (with $p=0.1$ to retain variables) using SST, temperature at $10 \mathrm{~m}$, and surface and water-column maximum chl $a$ indicate that overall abundance was related (positively) only to the chl a maximum, most strongly when log abundance was used $(F=$ 15.515, $\mathrm{p}=0.0001$ ). The same positive relationships with chl $a$, with somewhat reduced p levels, apply to each population component: nauplii, copepodids, and adults.
There was no correlation of egg abundance with either temperature or food $(F<2, \mathrm{p}>0.05)$. Perhaps of greater interest, stepwise regression revealed a significant negative influence of chl a maximum on the distribution of eggs per female $(F=5.143, \mathrm{p}<0.05)$.

Among stations, there were large differences in stage-frequency distributions during the broad-scale survey. Average stage of development (assuming 12 stages, NI to adult, with grouped nauplii taken as stage 3) was not related (stepwise regression at $p$ to retain $=0.1$ ) to temperature or chl a. Nor did there appear to be spatial patterns in stage-frequency distributions among stations. On a larger scale, the stage-frequency distributions in each of the 3 broad localities (15 stations combined in the Bay of Mejillones, 30 stations off the Mejillones Peninsula, and 8 stations off Antofagastasee Fig. 1) differed strongly (contingency $\chi^{2}=17746$, $p<10^{-7}$ ). Even within a limited area of the Bay of Mejillones, there were large differences among stations (Fig. 4; contingency $\chi^{2}=7949, \mathrm{p}<10^{-7}$ ). Cluster analysis of the rank correlations among stations in the Bay of Mejillones revealed inconsistent groupings of nearby 


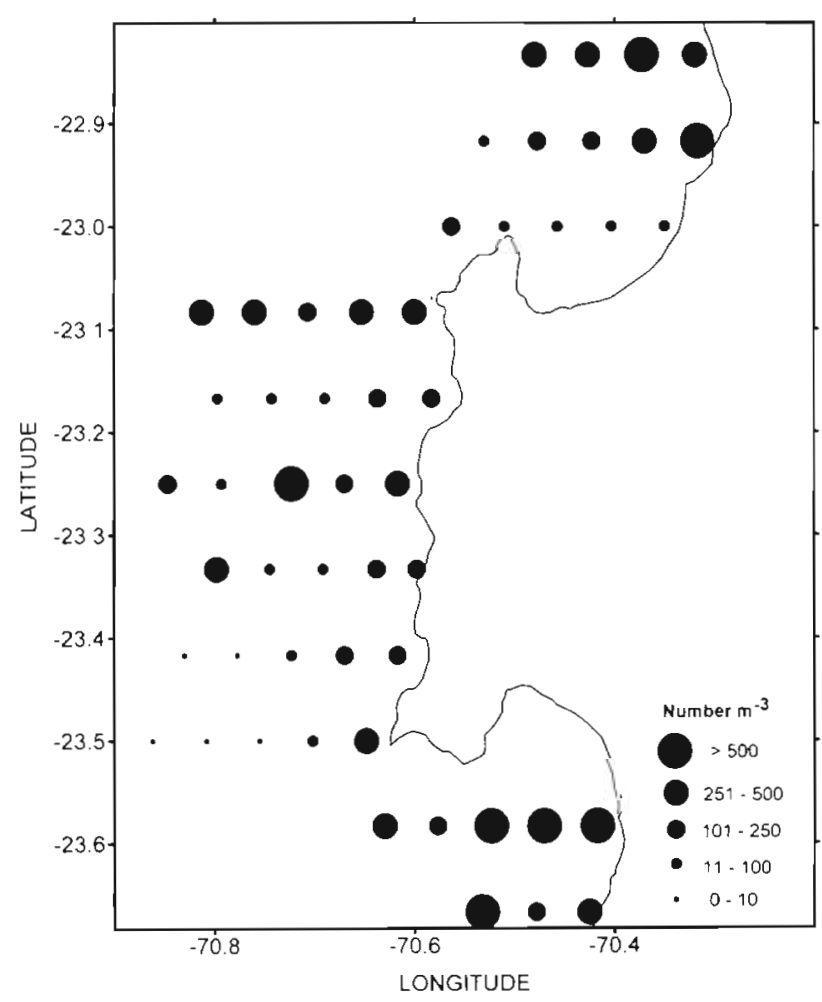

Fig. 3. Distribution of Calanus chilensis in December 1996 in the coastal area of the Mejillones Peninsula in the upper $200 \mathrm{~m}$ layer. Abundance for each station was obtained from mean values between the 2 sampling strata: $200-50 \mathrm{~m}$ and $50-0 \mathrm{~m}$ depth and includes all copepodites and nauplii stages stations, and overall there was no relationship between similarities of stage distributions (rank correlations) and distances among stations $(r=0.04, p>0.05)$.

In summary, while abundances of Calanus chilensis were positively related to chlorophyll concentrations, 2 potential measures of the effects of chl a on production (mean stages of development, eggs per female) were either negative or non-significant.

\section{Annual cycles in the Bay of Mejillones}

The annual cycles of temperature and chl a (Fig. 5) show the relatively high chl a levels through much of the year, and the usual development of stratification during the austral summer. However, Fig. 5 also shows that the normal seasonal pattern of temperature was altered by the onset of El Niño 1997, which produced an abrupt warming and deepening of the thermocline by May 1997, preceded by a sharp near-surface chlorophyll maximum.

Abundances and stage-frequency distributions of Calanus chilensis varied greatly through the year, although numbers were generally higher in winter and lower in the summer (Fig. 6). It might seem tempting to trace cohorts in the seasonal stage-frequency distributions (for example, suggesting that adults on June 23 produced the many eggs and nauplii observed on July 9 , and in turn giving rise to the copepodids and adults

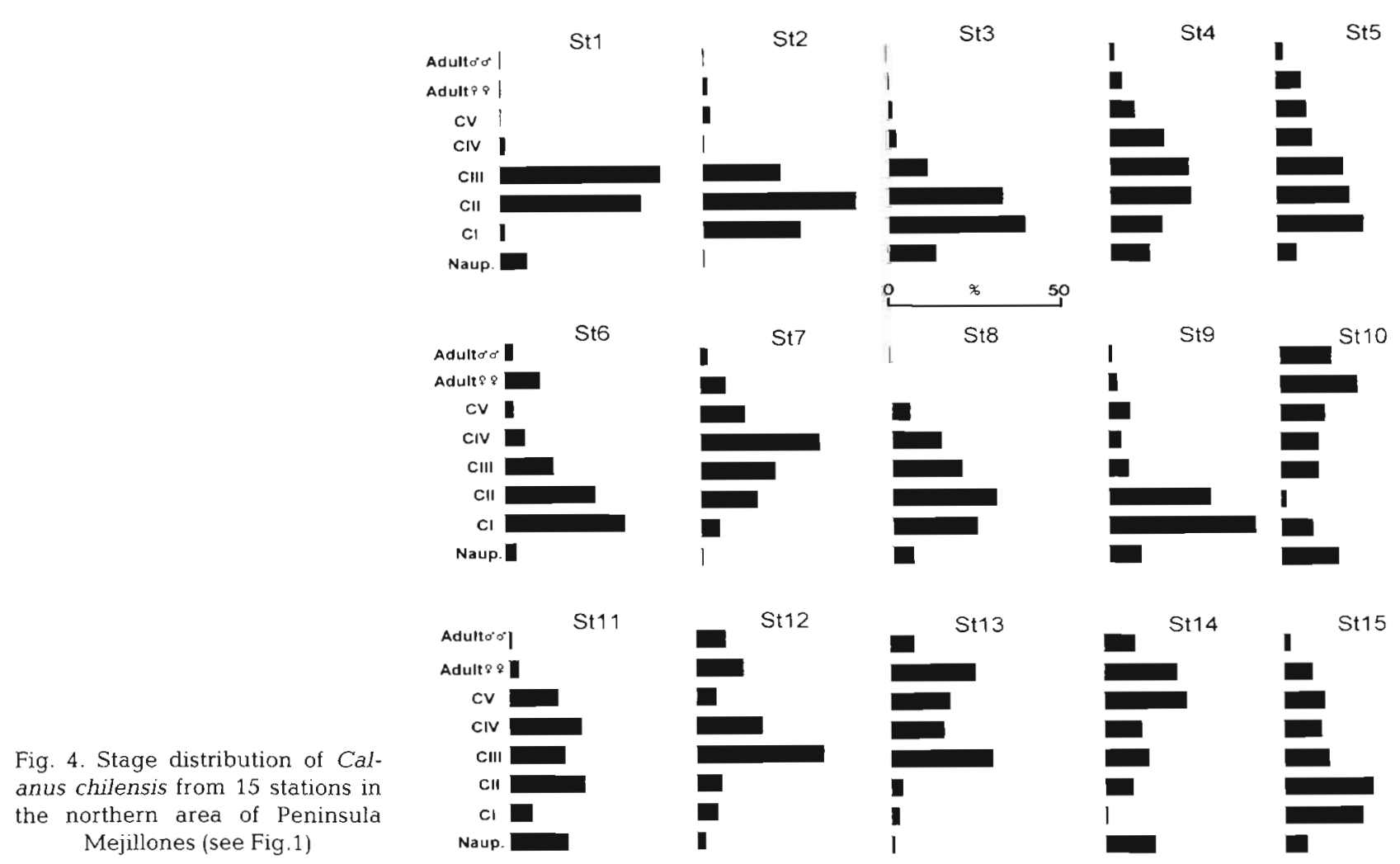




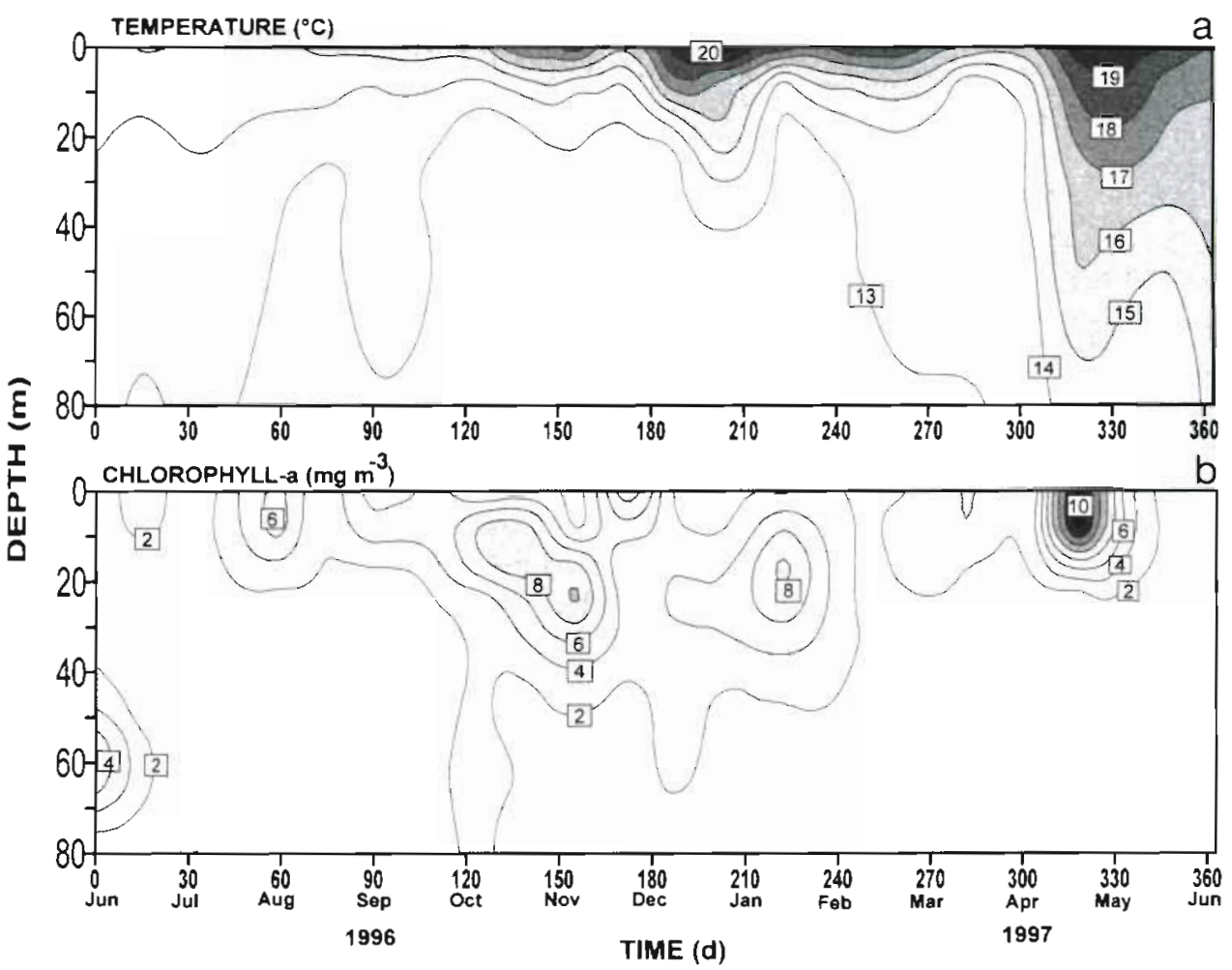

Fig. 5. The seasonal cycle of (a) temperature and (b) phytoplankton biomass in the Bay of Mejillones during June 1996 and July 1997, obtained from $\sim 15 \mathrm{~d}$ interval profiles from 3 stations. Contours were constructed from every $5 \mathrm{~m}$ depth of resolution from surface to bottom
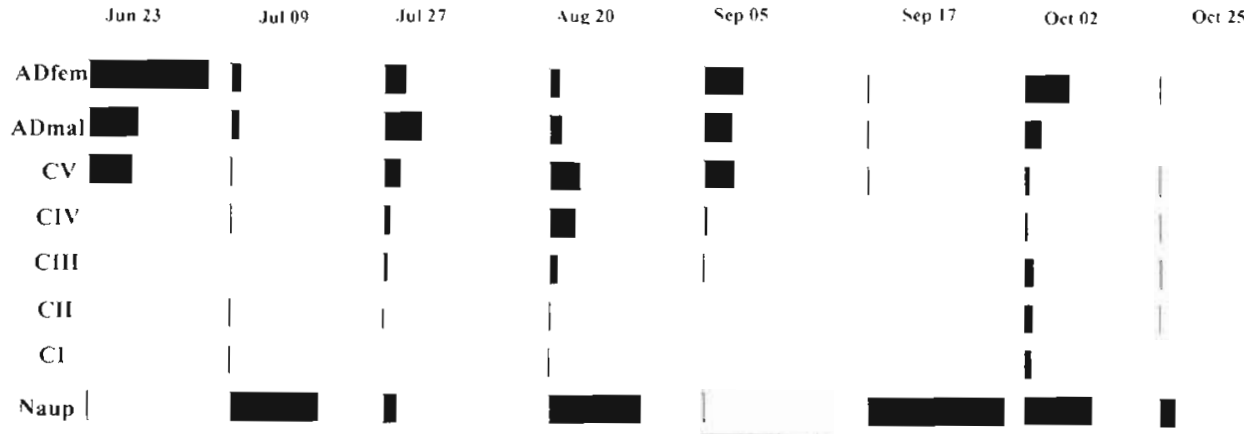

$\operatorname{Tav} 07$

Nor 26

Dee 13

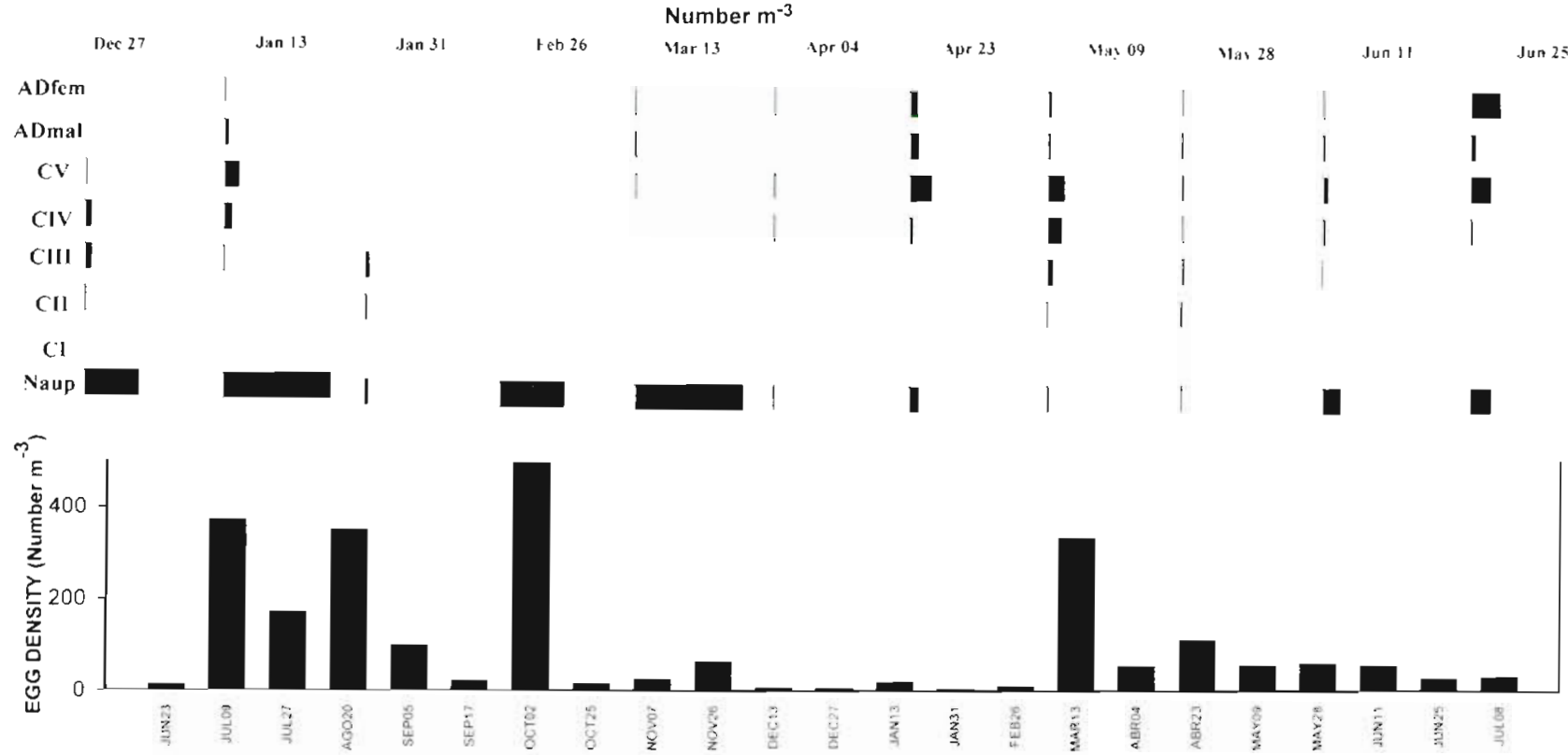

Fig. 6. Stage distribution and abundance of Calanus chilensis during a year cycle in the Bay of Mejillones. Stage abundances are estimated from mean values from 3 stations (Fig. 1), sampled from near the bottom (ca $90 \mathrm{~m}$ ) to surface 
found on July 27). This would be unwise for 2 reasons. First, the great spatial variation in stage-frequency distributions (Fig. 4) precludes assumption that cohorts are widely synchronous. Second, the mean sampling interval of $\sim 17 \alpha$ is not far short of generation times predicted from temperatures during the year (ca $22 \mathrm{~d}$, Table 1). Much overlapping of cohorts must result from continuous production, because eggs were always present (Fig. 6). Moreover the number of eggs per female although variable remained high most of the year (Fig. 7).

At the end of May, the onset of El Niño 1997 was accompanied by an almost complete disappearance of Calanus chilensis from samples. However, by late June, numbers were restored to levels approaching those of the previous June.

\section{Lengths, weights, and production}

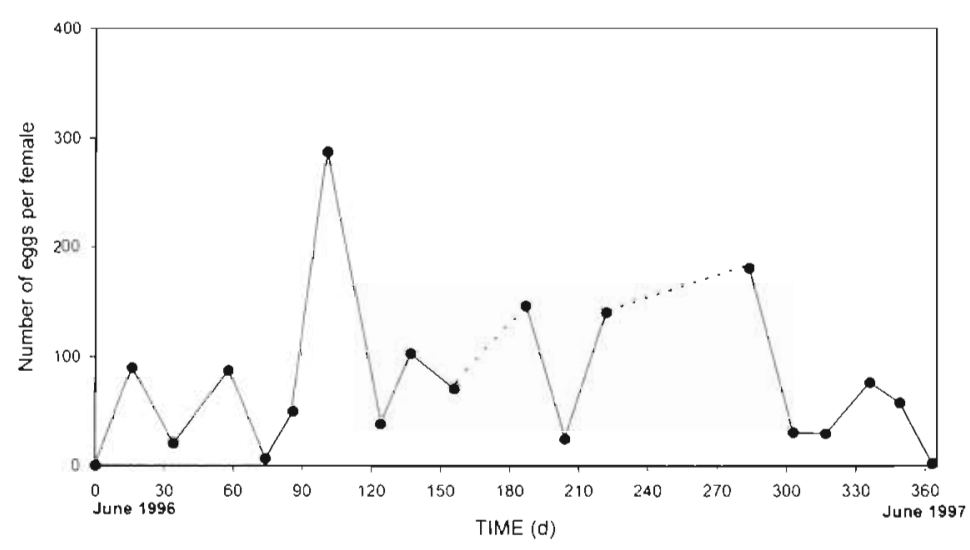

Fig. 7. The ratio between number of eggs and female abundance of Calanus chilensis during a year cycle 1996-1997. The sampling interval is roughly $15 \mathrm{~d}$ and dotted lines represent interpolations in periods when females were absent

mean chl a concentration in the upper $50 \mathrm{~m}$, which was high in the spring, low in the summer, and again high in the fall (Fig. 5). Female dry weight showed no association with either temperature, or chl a.

The temperature-dependent stage durations and

Here we estimate production on the assumption that it is determined by temperatures at the times of sampling. This procedure is justified in the discussion.

Dry weights and body lengths were obtained directly for copepodids and adults present on each sampling date, and weights of eggs and nauplii assumed as indicated in 'Methods'. Adult female dry weights and lengths were higher in winter-spring and declined sharply in summer (Fig. 8). Decline of body size was associated with increasing temperatures towards summer and fall (Fig. 5). Body length was negatively associated with temperature at $10 \mathrm{~m}$ depth (stepwise regression, $F=13.051, p<0.01$ ), but not with

Table 1. Temperature-dependent stage durations and instantaneous growth rates $\left(g_{1}\right)$ of Calanus chilensis during the annual cycle in Bay of Mejillones, from June 1996 to June 1997. Mean values and standard deviations (SD) are from $\mathrm{n}=22$. Stages durations and $\mathrm{g}_{1}$ were estimated using Eq. (1) and (3) (see text) and using the mean temperature at $10 \mathrm{~m}$ depth measured at 3 stations in the Bay of Mejillones (Fig. 1)

\begin{tabular}{|lcccc|}
\hline $\begin{array}{l}\text { Stage } \\
\text { or phase of } \\
\text { development }\end{array}$ & $\begin{array}{c}\text { Stage duration } \\
\text { (d) }\end{array}$ & Mean & SD & \multicolumn{2}{c|}{$\begin{array}{c}g_{1} \\
\left(\mathrm{~d}^{-1}\right)\end{array}$} \\
\hline Hatching-CI & 8.5 & 0.87 & 0.045 & SD \\
CI & 1.9 & 0.19 & 0.335 & 0.177 \\
CII & 2.1 & 0.22 & 0.240 & 0.111 \\
CIII & 2.3 & 0.24 & 0.354 & 0.180 \\
CIV & 2.7 & 0.29 & 0.313 & 0.113 \\
CV & 4.7 & 0.50 & 0.092 & 0.049 \\
Total & 22.2 & & & \\
\hline
\end{tabular}
Growth rate changed only moderately through time, although it does not closely follow the temperature pattern. Although the growth rates are driven by a positive effect of temperature on development rate, the apparent lack of effect on body weights (negative on body lengths, and perhaps on weights with larger sample sizes) obscures this positive effect development rates. Daily production rates on the other hand show drastic variability, according to differences of biomass, although there is a lack of any seasonal pattern associated with either temperature or food (Fig. 9).

Using the stage-by-stage growth rates and biomasses, estimated daily production rates and corresponding total biomasses for each time interval; integrated annual production was calculated as $45.4 \mathrm{mg}$ dry weight $\mathrm{m}^{-3}$, corresponding to $\mathrm{ca} 1.12 \mathrm{~g} \mathrm{C} \mathrm{m}^{-2} \mathrm{yr}^{-1}$, assuming $40 \%$ of carbon content from the dry weight and taking a mean depth of the 3 sampling stations as $62 \mathrm{~m}$. The mean annual biomass of about $1 \mathrm{mg}$ dry weight $\mathrm{m}^{-3}$ yields a $\mathrm{P} / \mathrm{B}$ ratio of about 45 .

The biomass of Calanus chilensis during December 1996 was unevenly distributed in the area, following the distributional pattern of adult females. Distribution of the daily production rates was, as expected, highly associated with that of biomass. The mean daily production of C. chilensis for the 53 stations was $1.57 \mathrm{mg}$ dry weight $\mathrm{m}^{-3} \mathrm{~d}^{-1}$, with a standard deviation of 1.706 . Integrating in the water column down to $200 \mathrm{~m}$, this yields $126 \mathrm{mg} \mathrm{C}$ $\mathrm{m}^{-2} \mathrm{~d}^{-1}$ as an average for the $3 \mathrm{~d}$ sampling period.

Spatial variability of biomass in the whole area might explain the apparent low annual production in the Bay 


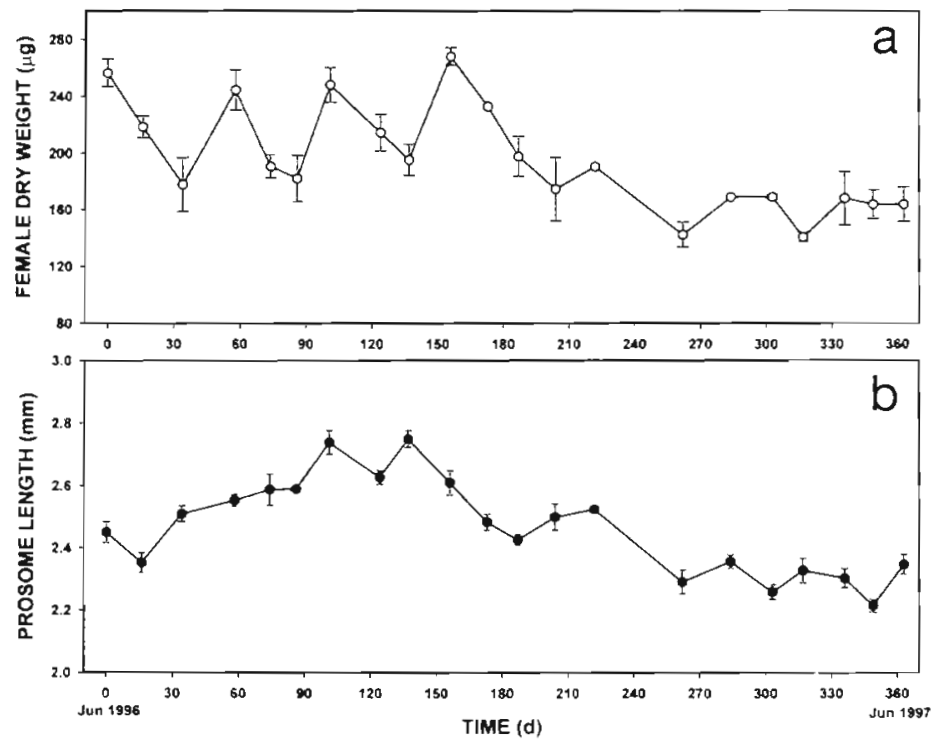

Fig. 8. (a) Female dry weight and (b) female prosome length of Calanus chilensis in the Bay of Mejiliones during its annual cycle 1996-1997. Values are means from $n>5$ for dry weight and $n>20$ for length and vertical bars are standard errors

of Mejillones. For instance, on December 13, a few days prior to the survey, the estimate of daily production for the 3 stations inside the bay was extremely low, ca $0.9 \mu \mathrm{g}$ dry weight $\mathrm{m}^{-3}$ when only nauplii were present (Fig. 6). This estimate is orders of magnitude lower than the average for the broad-scale survey. Low biomass of Calanus chilensis in the Bay of Mejillones is evident from Fig. 3, and this might well be a frequent situation in the area during the annual cycle.

\section{DISCUSSION}

The critical assumption in our estimates of production is that growth and development were determined by prevailing temperatures and unaffected by the quantity or quality of available food. The temperature-dependence of development rates could not be directly tested from successions of distinguishable cohorts in the time-series samples. However, there is some indirect evidence that food supply is unimportant.

(1) The lack of correlation in the broadscale survey between levels of chlorophyll a and mean stage of development suggests that copepod development was locally neither retarded nor accelerated in relation to food supply.

(2) The year-long series revealed no evidence of possible responses of aspects of life histories to food shortages. Development did not become stalled in particular stages (for example in copepodid resting stages) during the year-long study. Rather, nauplii, copepodids, and adults were present in varying proportions in virtually all samples. In particular, adult males, which indicates recent maturation in other Calanus species because they are short-lived (e.g. Marshall \& Orr 1955), were present in most samples (Fig. 6). Furthermore, the number of eggs per female in the samples (Fig. 7), while very variable, showed no seasonal patterns that might reflect food shortages and was not associated with either mean chl a in the upper $50 \mathrm{~m}$, or temperature at $10 \mathrm{~m}$ (stepwise regressions, $F<1, \mathrm{p}>0.05$ ). The weak negative relationship between number of eggs per female and chl a levels in the broad-scale survey again suggest that egg production was unaffected by food supply during that time. (The negative effect is inexplicable, without ad hoc explanations involving, perhaps, differential distribution of egg predation.)

(3) The decline of both body length and weight of females towards the warm season might appear to suggest that cohorts were experiencing poor conditions for maximal growth and development rates. However, female body length in the time series was related to temperatures, not chlorophyll, and body weight (based on smaller sample sizes) was not related to either. It is known that higher temperatures may reduce final size in ectotherms (Atkinson 1994), including copepods (Uye 1988, Escribano \& McLaren 1992, Carlotti et al. 1993).

Assuming that production rates were indeed dependent on temperature alone, our estimation procedures can also be justified.

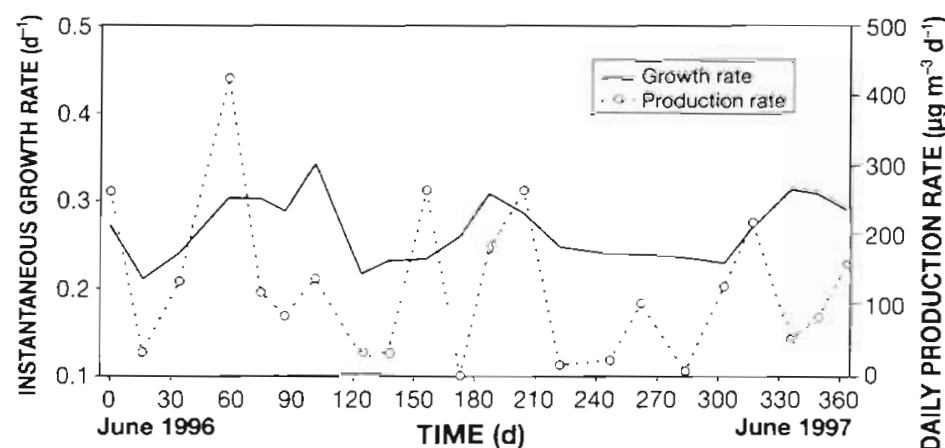

Fig. 9. Variability of the weight-specific growth rate an daily production rate of Calanus chilensis in B. Mejillones during its annual cycle 1996-1997. Weight-specific growth rate $\left(g_{l}\right)$ was estimated as temperature-dependent and production rate by biomass estimated from dry weights of all developmental stages 
(1) The Beléhrâdek equation is simple in form and its parameters are related to some other features of animal responses to temperature (McLaren 1995). Here we have used it only as an empirical convenience when assuming the same relative stage durations found in other Calanus species. The production estimates would not be noticeably affected by choice of a particular temperature function.

(2) Because of the possible inadequacy of estimated development times of later copepodids of Calanus chilensis in laboratory experiments, we have used estimates based on the similarity of relative times among other Calanus species, as justified in our 'Methods' section.

There was great local variation in abundance of Calanus chilensis, and its correlation with surface chl a need not imply a direct, causal relationship. It could, for example, result from common hydrographic processes (e.g. Lindahl \& Perissinoto 1987) or copepod motility in relation to small-scale concentrations of food (e.g. Garcia-Soto et al. 1990, Cowles et al. 1993). Abundances were generally smaller at stations inside the northern bay than elsewhere, and in particular in the southeast part of the Bay of Mejillones (Fig. 3). Upwelling with advection offshore may have produced some of the variation among stations. Advection is a relevant factor in upwelling zones (Smith 1968). Strong offshore currents of the surface Ekman layer may cause large displacement of passive populations (e.g. Wroblewski 1980). This seems to strongly affect distribution of $C$. chilensis in northern Chile (Gonzalez \& Marin 1998). Although in vertically stratified systems zooplankton can use current shear to maintain vertical position (e.g. Peterson et al. 1979), C. chilensis copepodids tend to accumulate offshore because of advection (Gonzalez \& Marin 1998). Younger copepodids were relatively more abundant at the outermost stations in the Bay of Mejillones, whereas older copepodids and adults predominated in the much smaller populations at stations in the inner and southern parts of the bay (Fig. 4). This is perhaps consistent with younger animals being swept out by the offshore currents, with older ones better able to take advantage of shear conditions for maintaining their positions

The variation in stage-frequency distributions among samples from the December survey, and the lack of coherence of mean stage of development among nearby samples, suggests that cohorts were spawned and developed without the wide synchrony that is imposed by seasonality in some temperate localities (e.g. Solow \& Steele 1995). The homogenizing forces of diffusion and advection were evidently not enough to eliminate the effects of local population histories in the area. Both abundances and stage-frequency distributions could also have been subjected to locally varying predation regimes.
Whatever the sources of the great local variation in abundance and population structure, it casts doubt on the wider applicability of the estimates of annual production at 3 stations in the Bay of Mejillones. The estimated annual production of Calanus chilensis at $45 \mathrm{mg}$ dry weight $\mathrm{m}^{-3}$, even though production is sustained through the year, is lower than that of Calanus finmarchicus on Georges Bank (Canada), estimated as $76.2 \mathrm{mg} \mathrm{C} \mathrm{m}{ }^{-3}$ (Davis 1984), equivalent (at $\mathrm{C} / \mathrm{dry}$ weight $=0.40$ ) to $190 \mathrm{mg}$ dry weight $\mathrm{m}^{-3}$, or on the Scotian Shelf, eastern Canada, estimated as $122 \mathrm{mg}$ dry weight $\mathrm{m}^{-3}$ (McLaren et al. 1989a). If the relatively low biomasses of $C$. chilensis during December 1996 in southern Bay of Mejillones prevailed at other times of year, then annual production may have been much higher in the wider upwelling area off northern Chile. The annual $\mathrm{P} / \mathrm{B}$ of 45 in the Bay of Mejillones, compared with $\mathrm{P} / \mathrm{B}$ of $\sim 8$ on the Scotian Shelf (McLaren et al. 1989a), is more in keeping with the general view that the former is part of one of the world's most productive marine systems.

Acknowledgements. This work has been funded by FONDECYT-Chile, Grant $196 / 1265$ to R.E. It is also a contribution to the FONDAP-HUMBOLDT Program of CONICYT-Chile, which provided additional support. I.M. research is supported by an operating grant from the Natural Science and Engineering Research Council of Canada. Valuable comments from anonymous reviewers have helped improved earlier versions of this work.

\section{LITERATURE CITED}

Atkinson D (1994) Temperature and organism size: a biological law for ectotherms? Adv Ecol Res 25:1-58

Carlotti F, Nival S (1992) Moulting and mortality rates of copepods related to age within stage: experimental results. Mar Ecol Prog Ser 84:235-243

Carlotti F, Krause M, Radach G (1993) Growth and development of Calanus finmarchicus related to the influence of temperature: experimental results and conceptual model Limnol Oceanogr 38: 1125-1134

Corkett CJ, McLaren IA, Sevigni JM (1986) The rearing of the marine calanoid copepods Calanus finmarchicus (Gunnerus), C. glacialis Jashnov and C. hyperboreous Kroyer with comments on the equiproportional rule. Syllogeus Nat Museum Can 58:539-546

Cowles S, Desiderio A, Neuer S (1993) In situ characterization of phytoplankton from vertical profiles of fluorescence emission spectra. Mar Biol 115:217-222

Davis CS (1984) Predatory control of copepods seasonal cycle on Georges Bank. Mar Biol 82:31-40

Deevey GB (1964) Annual variations in length of copepods in the Sargasso Sea off Bermuda. J Mar Biol Assoc UK 44 $589-600$

Escribano R, McLaren IA (1992) Influence of food and temperature on body weights of two Calanus species. I Exp Mar Biol Ecol 159:135-140

Escribano R, Rodriguez L (1994) The life cycle of Calanus chilensis Brodsky in Bay of San Jorge, Antofagasta, Chile Hydrobiologia 292/293:289-394 
Escribano R, Rodriguez L (1995) Size variation and growth in Calanus chilensis Brodsky in northern Chile. Rev Chil Hist Nat 68:373-382

Escribano R, Irribarren C, Rodriguez L (1997) The influence of food quantity and temperature on development and growth of Calanus chilensis from northern Chile. Mar Biol 28:281-288

Escribano R, Rodriguez L, Irribarren C (1998) Temperaturedependent development and growth of Calanus chilensis from northern Chile. J Exp Mar Biol Ecol 229:19-34

Fonseca TR, Farias M (1987) Estudio del proceso de surgencia en la costa Chilena utilizando percepcion remota. Invest Pesq 33:36-46

Garcia-Soto C, Madariaga I de, Villate F, Orive E (1990) Dayto-day variability in the plankton community of a coastal shallow embayment in response to changes in river runoff and water turbulence. Estuar Coast Shelf Sci 31:217-229

Gonzalez A, Marin V (1998) Distribution and life cycle of Calanus chilensis and Centropages brachiatus (Copepoda): a GIS approach. Mar Ecol Prog Ser 165:109-117

Heinrich AK (1973) Horizontal distribution of copepods in the Peru current region. Oceanology 13:97-103

Huntley ME, Lopez MDG (1992) Temperature-dependent production of marine copepods: a global synthesis. Am Nat $140: 201-242$

Kleppel GS, Davis CS, Carter K (1996) Temperature and copepod growth in the sea. Am Nat 148:397-407

Lindahl O, Perissinoto P (1987) Short-term variations in the zooplankton community related to water exchange in the Gullmar fjord, Sweden. J Plankton Res 9:1113-1132

Lopez MDG (1991) Molting and mortality depend on age and stage in naupliar Calanus pacificus: implications for development of field cohorts. Mar Ecol Prog Ser 75:79-89

Marin V, Rodriguez L, Vallejo L, Fuenteseca J, Oyarce E (1993) Efecto de la surgencia costera sobre la productividad primaria primaveral de bahía Mejillones del Sur (Antofagasta, Chile). Rev Chil Hist Nat 66:479-491

Editorial responsibility: Otto Kinne (Editor)

Oldendorf/Luhe, Germany
Marshall SM, Orr AP (1955) The biology of a marine copepod Calanus finmarchicus (Gunnerus). Oliver \& Boyd, Edinburgh

McLaren IA (1978) Generation lengths of some temperate marine copepods: estimation, prediction, and implications J Fish Res Bd Can 35:1330-1342

McLaren IA (1995) Temperature-dependent development in marine copepods: comments on choices of models. J Plankton Res 31:1342-1346

McLaren IA, Sevigni JM, Corkett CJ (1989a) Temperaturedependent development in Pseudocalanus species. Can J Zool 67:559-564

McLaren IA, Tremblay MJ, Corkett CJ, Roff JC (1989b) Copepod production on the Scotian Shelf based on life-history analyses and laboratory rearings. Can J Fish Aquat Sci $46: 560-583$

Omori M, Ikeda T (1984) Methods in marine zooplankton ecology. John Wiley \& Sons, New York

Peterson WT, Miller CB, Myers AH (1979) Zonation and maintenance of copepod populations in the Oregon upwelling zone. Deep-Sea Res 26:467-494

Rodriguez L, Marin VA, Farias M, Oyarce E (1991) Identification of an upwelling zone by remote sensing and in situ measurements, Mejilones del Sur Bay (Antofagasta-Chile). Scient Mar 55:467-473

Smith RL (1968) Upwelling, oceanography and marine biology. Ann Rev Bull 6:11-46

Strickland JDH, Parsons TR (1972) A practical handbook of seawater analysis. Fish Res Bd Can 167:310

Solow AR, Steele, JH (1995) Scales of plankton patchiness: biomass versus demography. J Plankton Res 17:1669-1677

Uye S (1988) Temperature-dependent development and growth of Calanus sinicus (Copepoda:calanoida) in the laboratory. Hydrobiologia 167/168:285-293

Wroblewski JS (1980) A simulation of the distribution of Acartia clausi during Oregon upwelling, August 1973. J Plankton Res 2:43-68

Submitted: March 26, 1998; Accepted: September 19, 1998 Proofs received from author(s): February 3, 1999 